Review

\title{
Role of Physicochemical Properties in Nanoparticle Toxicity
}

\author{
Seung Won Shin ${ }^{1}$, In Hyun Song ${ }^{1}$ and Soong Ho Um ${ }^{1,2, *}$
}

1 School of Chemical Engineering, Sungkyunkwan University, Suwon, Gyeonggi-do 440-746, Korea; E-Mails: seung3885@skku.edu (S.W.S.); songinhyun@skku.edu (I.H.S.)

2 SKKU Advanced Institute of Nanotechnology (SAINT), Sungkyunkwan University, Suwon, Gyeonggi-do 440-746, Korea

* Author to whom correspondence should be addressed; E-Mail: sh.um@skku.edu;

Tel.: +82-31-290-7348; Fax: +82-31-290-7272.

Academic Editor: Robert Tanguay

Received: 11 May 2015 / Accepted: 12 August 2015 / Published: 19 August 2015

\begin{abstract}
With the recent rapid growth of technological comprehension in nanoscience, researchers have aimed to adapt this knowledge to various research fields within engineering and applied science. Dramatic advances in nanomaterials marked a new epoch in biomedical engineering with the expectation that they would have huge contributions to healthcare. However, several questions regarding their safety and toxicity have arisen due to numerous novel properties. Here, recent studies of nanomaterial toxicology will be reviewed from several physiochemical perspectives. A variety of physiochemical properties such as size distribution, electrostatics, surface area, general morphology and aggregation may significantly affect physiological interactions between nanomaterials and target biological areas. Accordingly, it is very important to finely tune these properties in order to safely fulfill a bio-user's purpose.
\end{abstract}

Keywords: nanotoxicology; nanomaterials; physiological properties

\section{Introduction}

Since basic concepts of nanotechnology were introduced in the mid-twentieth century by Richard Feynman, Norio Taniguchi and Eric Drexler, a large body of literature on nanomaterials has accumulated and has expanded significantly in the twenty first century (Figure 1 and Table 1). Furthermore, the rapid development of methods and tools for nanomaterial/colloid characterization has 
resulted in substantial advances in materials (i.e., fullerene and carbon nanotubes) [1]. Inspired by these trends, many scientists now favor nanomaterials with new characteristics over outdated bulky materials. As of the early 2000s, these newer materials have begun to deepen their impact on our daily lives in applications such as clothing, cosmetics, furniture, and even foods.

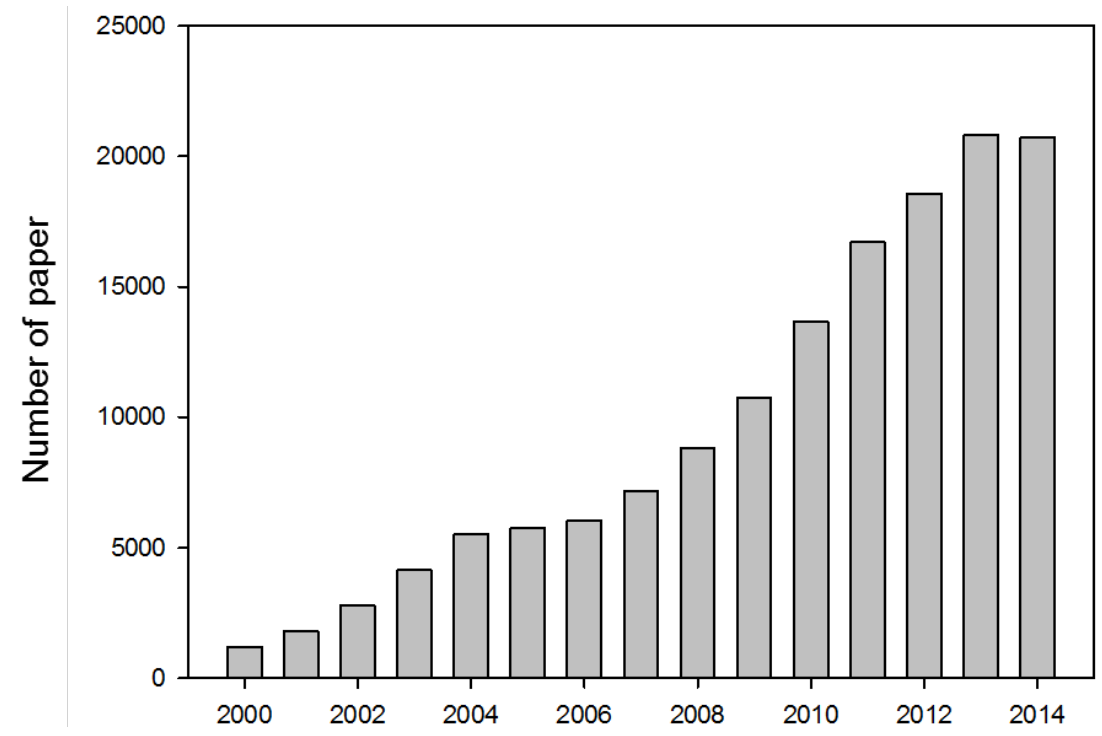

Figure 1. The number of nanoscience papers indexed in Scopus between 2000 and 2014. Source: "Nanoparticle", data from Scopus.

Table 1. Detail information about the graph was described in the table. Highly cited authors, country, and subject area are used as specific subsection of papers. Source: "Nanoparticle", data from Scopus.

\begin{tabular}{|c|c|c|c|c|c|}
\hline Author & Papers & Country & Papers & Subject area & Papers \\
\hline Couvreur, P. & 250 & United States & 39,702 & Chemistry & 62,277 \\
\hline Mirkin, C.A. & 244 & China & 31,406 & Materials Science & 59,895 \\
\hline Rotello, V.M. & 227 & India & 10,590 & Physics and Astronomy & 40,126 \\
\hline Muller, R.H. & 199 & Germany & 10,180 & Chemical Engineering & 40,108 \\
\hline Kreuter, J. & 186 & Japan & 9,951 & Engineering & 36,940 \\
\hline \multirow{2}{*}{ Weissleder, R. } & \multirow{2}{*}{185} & \multirow{2}{*}{ South Korea } & \multirow{2}{*}{9,118} & Biochemistry & \multirow{2}{*}{30,209} \\
\hline & & & & Genetics and Molecular Biology & \\
\hline Yuan, R. & 170 & United Kingdom & 6,809 & Medicine & 21,275 \\
\hline \multirow{2}{*}{ Xia, Y. } & \multirow{2}{*}{149} & \multirow{2}{*}{ France } & \multirow{2}{*}{6,484} & Pharmacology & \multirow{2}{*}{18,456} \\
\hline & & & & Toxicology and Pharmaceutics & \\
\hline Lanza, G.M. & 148 & Italy & 4,457 & Environmental Science & 8,709 \\
\hline Wickline, S.A. & 146 & Spain & 4,306 & Others & 21,726 \\
\hline
\end{tabular}

The nanomaterials market has exploded. For example, titanium dioxide $\left(\mathrm{TiO}_{2}\right)$ nanoparticles, which are a major ingredient in sunblock, absorb ultraviolet (UV) light and efficiently protect skin from harmful UV light exposure. They are also used in many cosmetics. In addition, silica dioxide $\left(\mathrm{SiO}_{2}\right)$ is often used as a food additive to decrease viscosity and regulate acidity. Owing to their powerful anti-microbial and light-weight characteristics, silver $(\mathrm{Ag})$ nanoparticles and carbon nanotubes (CNTs) 
are used extensively in a variety of cleansers and in sporting equipment. However, its safety is continuously debated among many scientists and clinicians.

The cytotoxicity of nanoparticles is induced by several factors. Some cases of nanomaterials inducing cytotoxicity are because of the substance itself, and some nanoparticles show toxicity without clear mechanism [2,3]. Some nanoparticles of a particular substance are thought to pose greater risks of toxicity than larger-sized particles of the same substance [4-6]. Above all, the distribution of particles within the body and the accumulation of a specific type of particle in a particular part of the body, which is dependent on the particle's size and surface characteristic, are considered critical issues [7]. Also, when the nanoparticles accumulate in body system without proper excretion, it can cause continuous toxicity. The main distribution sites and target organs for nanoparticles are unknown; however it appears that the liver and spleen may be target organs [8,9]. If nanoparticles are ingested, inhaled or absorbed through the skin, they can induce the formation of reactive oxygen species (ROS) including free radicals [10]. ROS produces oxidative stress, inflammation, and consequent damage to various biological materials such as protein, DNA, etc. Besides ROS production, other factors influencing toxicity include size, morphology, agglomeration statue, shape, chemical composition, surface structure, surface charge, aggregation and solubility [11]. As a result of their small size, nanoparticles can cross tissue junctions and even cellular membranes where they induce structural damage to the mitochondria [12,13] or invade the nucleus where they cause serious DNA mutations [14] leading to cell death [15]. The factors mentioned above can be categorized under the five characteristics of nanoparticle, which are: size; surface area; electrostatic statue of surface; morphology; and agglomeration status.

Researchers have made a substantial effort to minimize unwanted interactions between nanomaterials and biological tissues. Researchers have investigated surface coatings and other modifications to increase the safety of nanoparticles in the body. However, these surface coatings are protective for only a short time because they are destroyed over a period of one to four hours by environmental interactions such as air exposure or ultraviolet irradiation [16,17]. To overcome this shortage, several trials have been conducted and have shown a link between long term coating of nanoparticles and a significant reduction of cytotoxicity [18].

Some say that toxicological data for nanoparticles is lacking because of the short history of nanotechnology in healthcare. However, others insist that nanomaterials are safe for healthcare use $[19,20]$. To settle the debate, it is necessary to clarify the physicochemical properties of nanoparticles related to toxicity. In principle, nanomaterials distinguishable characteristics are mainly assumed to originate from either their surface area or mass quantity, and their lifespan is based on biological cellular interactions. Some of them are unstable at the surface, showing unusual communication with their biological neighbors. Many recent studies have shown that this instability could be minimized by modulating some physicochemical properties. In this short review, recent trends regarding the role of nanomaterials' physicochemical properties, in terms of in vitro and in vivo toxicological results, will be discussed (Figure 2). 


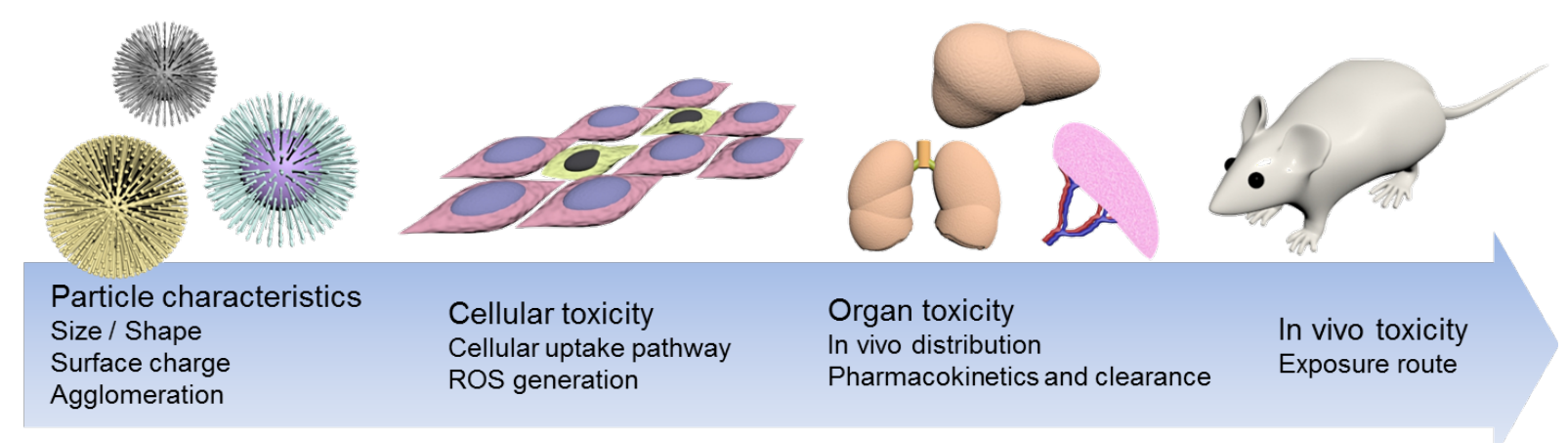

Figure 2. Schematic drawing of nanoparticle induced cytotoxicity. Intrinsic features of nanoparticles, such as size, surface charge, agglomeration, can significantly affect cytotoxicity. Such cytotoxicity can be affected at the levels of the cell, organ and even in vivo systems.

\section{Size}

Cytotoxicity is induced by nanomaterials results from the interaction between the nanomaterial surface and cellular components. As the diameter decreases, the surface area of the particle increases exponentially. Thus, even when particles have the same composition, they can have significantly different levels of cytotoxicity depending on both particle size and surface reactivity. Additionally, particle size induces significant differences in the cellular delivery mechanism and distribution in vivo. In this regard, not only are chemical properties and size-dependent cytotoxicity important in assessing a nanomaterial's cytotoxicity, but also is the amount of size-dependent cytotoxicity.

\subsection{Size-Dependent Absorption}

To generate cytotoxicity and inflammatory response in animal models, it is essential that the nanoparticles should migrate across the epithelial barrier. In this respect, the size of the nanoparticles plays a key role in cytotoxicity [21,22]. In the case of nanoparticle inhalation, nanoparticles penetrate deeply into the lung parenchyma. Different sized nanoparticles show specific distribution patterns in the respiratory tract. Nanoparticle distribution is also affected by the Stokes number and Reynolds number. Initially, particles are well distributed in the gas phase, but after inhalation they translocate into the liquid phase in respiratory fluids [23,24].

Recently, Braakhuis et al. assessed cytotoxicity induced by inhaled silver nanoparticles of different size [25]. They prepared 18, 34, 60, and $160 \mathrm{~nm}$ silver nanoparticles and exposed rats to different concentrations of the particles. After exposure, the rats were sacrificed and the amount of silver nanoparticles in their lungs was measured. They found that silver nanoparticles in sizes of 18 and $34 \mathrm{~nm}$ induced lactate dehydrogenase ( $\mathrm{LDH}$ ) expression, which is a marker of cell damage, in a dose-dependent manner after $24 \mathrm{~h}$. Meanwhile, there was no dose-dependent cell damage when 60 and $160 \mathrm{~nm}$ nanoparticles were used. Although there were more 60 and $160 \mathrm{~nm}$ nanoparticles measured in the lungs overall, more of the 18 and $34 \mathrm{~nm}$ nanoparticles were found in the alveoli. The authors indicated that the increased surface area of the nano-scaled particles was the most likely factor contributing to the toxicology of the silver nanoparticles. 


\subsection{Size-Dependent in Vivo Pharmacokinetics and Clearance}

The distribution of a drug or nanoparticles in vivo, or pharmacokinetics, is also an important consideration in assessing cytotoxicity. Many studies have examined the in vivo distribution of nanomaterials [26]. Nanoparticles with a diameter greater than $6 \mathrm{~nm}$ cannot be excreted by the kidneys and accumulate in specific organs, such as the liver and spleen, until clearance by the mononuclear phagocyte system ensues [27]. Most nanoparticles that accumulate the in liver and spleen cause serious side effects. For instance, cadmium selenide (CdSe) quantum dots remain in the tissue for up to eight months and cause hepatotoxicity [28]. This pharmacokinetic characteristic of nanoparticles is dependent on particle size and surface chemistry.

The in vivo distribution of gold nanoparticles according to size was evaluated by De Jong et al. [29]. They used particles from 10 to $250 \mathrm{~nm}$ in size and assessed in vivo distribution after intravenous injection in a rat model. They found that $10 \mathrm{~nm}$ nanoparticles were distributed differently than their larger counterparts. They were found in almost all organs, including the blood, liver, spleen, kidneys, testes, thymus, heart, lungs and brain. Meanwhile, most nanoparticles larger than $50 \mathrm{~nm}$ were detected only in the blood, liver and spleen. The distribution of nanoparticle in several organs is shown in Figure 3. This figure is reproduced from the work of De Jong et al. [29].

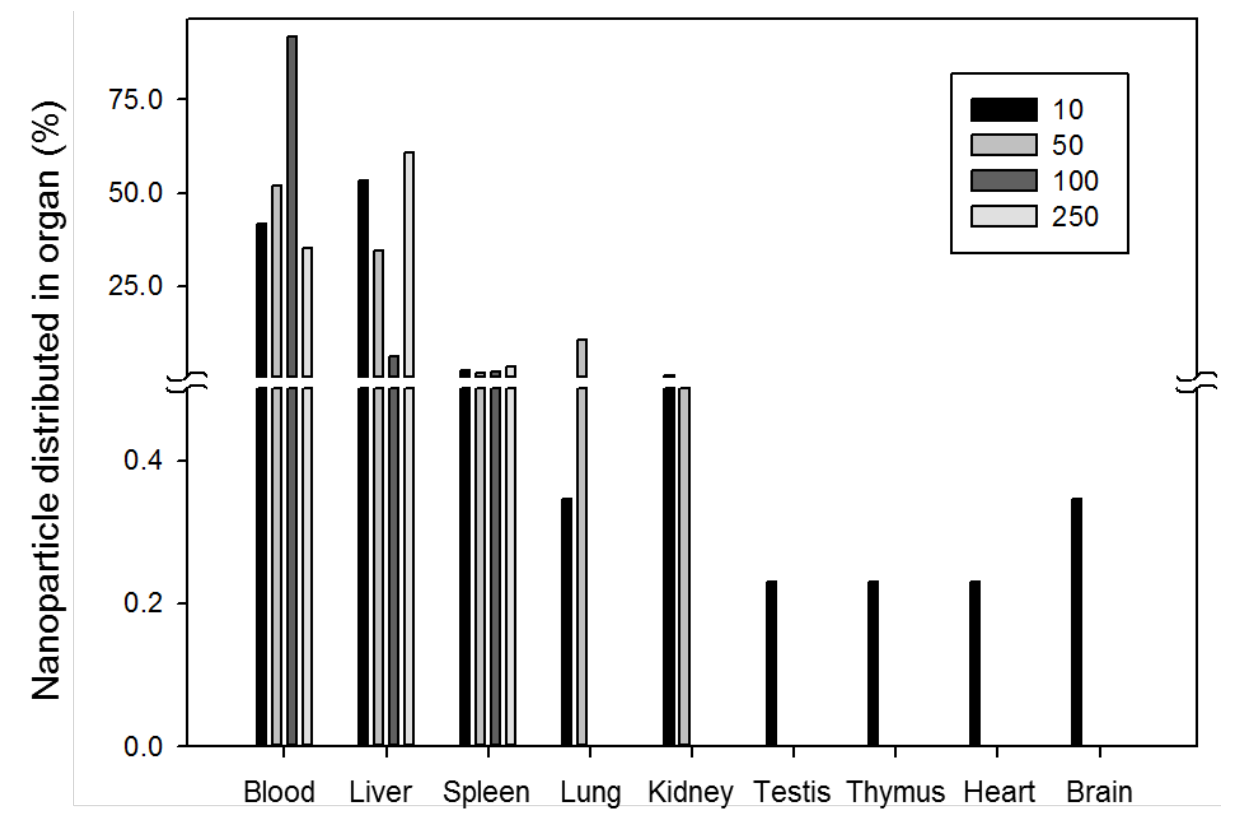

Figure 3. Gold nanoparticle distribution in several organs in rat according to particle size (nm).

\subsection{Size-Dependent Cellular Uptake and Cytotoxicity}

In terms of cellular interaction, nanoparticle uptake mechanism and efficiency are key factors influencing cytotoxicity. One of the major factors determining cellular uptake efficiency and mechanism is nanoparticle size. With respect to particle size and surface features, nanoparticles are internalized into the cell through various pathways, such as phagocytosis and pinocytosis. Several internalization pathways depend on size as noted in Table 2 [30,31]. Sizes suitable for uptake range from 10 to $500 \mathrm{~nm}$ with an upper limit of $5 \mathrm{~mm}$. Large particles are most likely to be engulfed via macropinocytosis. The size of a vesicle involved in clathrin-mediated endocytosis is about $100 \mathrm{~nm}$, 
while the size involved in caveolae-mediated endocytosis is usually about 60-80 nm. However, the examples in the literature also cite the uptake of particles larger than those size ranges.

Table 2. Examples of cellular internalization pathways of nanoparticles.

\begin{tabular}{|c|c|c|c|}
\hline Internalization pathway & Materials of particle & Particle diameter (nm) & Ref. \\
\hline \multirow{12}{*}{ Clathrin-mediated endocytosis } & {$\left[\mathrm{C}_{60}\left(\mathrm{C}(\mathrm{COOH})_{2}\right)_{2}\right]_{n}$} & 125 & [32] \\
\hline & PVA coated silver NP & 80 & [33] \\
\hline & PEGylated NP & 90 & [34] \\
\hline & LDH NP & $50-200$ & [35] \\
\hline & QD & 4 & [36] \\
\hline & Polystyrene NP & 100 & [37] \\
\hline & Pristine PS NP & $50-200$ & [38] \\
\hline & Silica NP & 110 & [39] \\
\hline & Herceptin-collidal gold NP & $2-100$ & [40] \\
\hline & Silica coated iron oxide NP & 20 & [41] \\
\hline & AuNR & & [42] \\
\hline & bombesin peptide conjugated AuNC & & [43] \\
\hline \multirow{6}{*}{ Caveolae-dependent endocytosis } & Derivatized fullerenes Baa-Lys(FITC)-(Lys) 8-OH & 4 & [44] \\
\hline & Perfl uorocarbon NP & 200 & [45] \\
\hline & Polysiloxane NP & 100 & {$[46]$} \\
\hline & fWGA-PLGA NP & 250 & [47] \\
\hline & Albumin-coated NP & $20-100$ & [48] \\
\hline & AuNR & $56 \times 13$ & [49] \\
\hline \multirow{6}{*}{ Pinocytosis/Macropinocytosis } & PVP-coated silver NP & 80 & [33] \\
\hline & Positively charged fluorescent polystyrene NP & 113 & [50] \\
\hline & Tat peptide-conjugated QD & & [51] \\
\hline & Silica NR & & [52] \\
\hline & Silver NP & 25 & [53] \\
\hline & IL-13 peptide conjugated PEG-PCL NP & $25-100$ & [54] \\
\hline
\end{tabular}

Gold nanoparticles typically form a surface coated with serum proteins when incubated with cells. Serum-layered gold nanoparticles usually induce receptor-mediated endocytosis, which is dependent on particle size. The uptake efficiency of gold nanoparticles as a function of size was evaluated by Chan et al. [55]. Gold nanoparticles ranging from 1 to $100 \mathrm{~nm}$ were incubated with Hela cells, and the $50 \mathrm{~nm}$ nanoparticle showed maximal uptake efficiency by receptor-mediated endocytosis [55]. A similar experiment using ligand-coated gold nanoparticles showed that a diameter of 40-50 nm was the critical cutoff point for receptor-mediated nanoparticle internalization [40]. This phenomenon is tightly related to the nanoparticle's binding and its cellular surface receptors. Extremely small nanoparticles have a surface curvature too great to provide necessary conformational rigidity to allow for multivalent binding with receptors. In contrast, larger nanoparticles cannot compensate for the depletion of receptors within the binding area through global diffusive motion of distant receptors, and this could limit the process of membrane wrapping that is necessary for nanoparticle internalization. As such, nanoparticles that are $40-50 \mathrm{~nm}$ in diameter seem to be the optimal size for both multivalent receptor interaction and binding rigidity. 
Differences in endocytosis efficiency naturally affect cellular cytotoxicity. The internalized nanoparticles generally translocate to endosomal or lysosomal vesicles for further elimination [16]. During this process, endosomal escape of internalized nanoparticles occurs, resulting in specific cytotoxicity through the production of ROS and direct mitochondrial damage.

\section{Surface}

In addition to size and surface charge, the particle surface itself also plays a critical role in biological toxicity.

\subsection{Surface Area}

Band gap alterations, decreased melting point, and higher reactivity induced by a large surface area were investigated [56-58] and it was found that these features had serious effects including lung inflammation, cytotoxicity and toxicity in vivo. A larger surface area may cause higher reactivity with nearby particles, resulting in possibly harmful effects when used in fillers, cosmetics, and as drug carriers [59]. It can be concluded that by decreasing the particle size, its biological activity increases substantially. Smaller particles occupy less volume, such that a larger number of particles can occupy a unit area, resulting in increased pathophysiological toxicity mechanisms, for instance oxidative stress, ROS generation, mitochondrial perturbation, etc. [60]. It has yet to be determined what features of nanoparticles cause such biological toxicity. It is presumed that the size of the nanoparticle alone may not be responsible for toxicity, but that the total number per unit volume may be important. To clearly comprehend the relationship between a nanoparticle's surface area and its biological toxicity, a group of researchers assessed acute lung inflammation with different nanoparticle surface areas and specific reactivity [61]. There were no significant differences in toxicity differences based on size; however, the total surface area played a critical role in lung inflammation. It has been clearly confirmed that pulmonary toxicity, assessed after treatment with several particles including carbon black, titanium dioxide, etc., may be induced by ultrafine and fine materials [62-64], which have large surface areas. Particle surface reactivity, characterized by how easily single particles aggregate, may also play a significant role in cytotoxicity [65-68]. It has also been suggested that dosing should be based on nanoparticle surface area.

\subsection{Surface Electrostatic Status}

Due to their small size, nanoparticles are usually used as a drug carrier via either passive or active transport. Their effective cellular internationalization depends upon biocompatibility $[27,69,70]$. In particular, external properties of surface electronic status are critical to cellular uptake and may also be involved in cytotoxicity. Traditionally, to study in vitro efficacy, nanocarriers are instilled into a 2D layered target cell for both therapeutic and diagnostic studies. However, such methodology should be reconsidered prior to in vivo study, because such a layered model may be dissimilar to that of a cell niche where cell to cell communications are critical for metabolic progress. Nonetheless, nanoparticles for delivery are currently designed based on ex vivo conditions mimicking tissue environments [71,72]. Similar methods are used to assess nanoparticle toxicology $[73,74]$. Higher uptake efficiency in a cell 
is achieved by replacing the surface functional moiety, inducing sudden changes in particles' surface charge $[75,76]$. Some authors have attempted to envelope nanoparticles in a lipid vesicle [77].

Changes in surface charge result in considerable differences in the in vivo biodistribution of nanoparticles. Even though some nanoparticles, including polymeric nanocomplexes and gold nanospheres, have the same range of size variations, different surface charges yielded marked discrepancies in both distribution and uptake efficiency. Particles showed different degrees of toxicity depending on their surface charges [78-81]. Nanoparticles with a positively charged surface tended to have much higher toxicity.

\section{Morphology}

Morphology is also a big issue in nanotoxicology. Like other well-established inhalable fibers (e.g., asbestos), nanoscaled fibers (e.g., carbon nanotubes) are reported to have a serious risk of lung inflammation. Furthermore, prolonged exposure may cause several cancers [82-84]. It is difficult to determine whether there is a certain toxic effect of single nanotubes or an ensemble of such tubes. Some studies have shown that carbon nanotubes are more toxic than other ultra-fine carbon black or silica dusts. Most workers exposed to single-walled carbon nanotubes (SWCNTs) beyond the current permissible exposure limit (PEL) developed lung lesions [85]. Interestingly, CNTs have been shown to cause death of targeted kidney cells via inhibited cell growth induced by decreased cell adhesiveness [86]. Human exposure to fullerene (also termed Buckyball) resulted in severe lung damage $[87,88]$ in addition to destruction of fish brain and water flea death [89-92].

\section{Agglomeration Status}

Irrespective of any physicochemical properties of nanoparticles, such as chemical composition, agglomeration could be a potent inducer of inflammatory lung injury in humans $[93,94]$. For certain types of chemicals, exposure at higher levels has been shown to lead to serious chronic diseases such as fibrosis and cancer [95]. It is still under consideration to figure out what features are inducing such toxicological effect in a living organism.

\section{Summary}

The ability to engineer nanometer-size materials has been proven to have great value in several fields, including basic science, such as chemistry, physics, biology and even engineering fields like biotechnology and electronics. Prior to the widespread introduction of such nanotechnology in medicine, its safety in biological systems should be investigated thoroughly. All physicochemical properties of nanoparticles should be evaluated in order to elucidate their interaction with subcellular organelles, cells, tissues, and organisms. Such investigations will provide us with strategies to engineer new generations of nontoxic products containing nanoparticles. These fundamental studies will help to generate criteria for the smart design of nanoparticle which can be used in vivo. 


\section{Acknowledgments}

This work was supported by grants from the Korea Health Technology R\&D Project through the Korea Health Industry Development Institute (KHIDI), funded by the Ministry of Health \& Welfare, Republic of Korea (grant no. HI14C3301) and by Basic Science Research Programs through the National Research Foundation (NRF) funded by the Ministry of Science ICT and Future Planning (Grant Nos. 2013R1A1A1058670 and 2013R1A1A2016781) and by the International Research \& Development Program of the National Research Foundation of Korea (NRF) funded by the Ministry of Science, ICT \& Future Planning (grant no. 2015K1A3A1A21000238).

\section{Author Contributions}

S.W.S. and I.H.S. designed the subject of review article and wrote the manuscript. S.W.S. and S.H.U. conceived the project, designed the subject, discussed several related articles, supervised the task, and wrote the manuscript. All authors reviewed and approved the manuscript.

\section{Conflicts of Interest}

The authors declare no conflict of interest.

\section{References}

1. Maskos, M.; Stauber, R.H. 3.319 - Characterization of nanoparticles in biological environments. In Comprehensive Biomaterials, Ducheyne, P., Ed.; Elsevier: Oxford, UK, 2011; pp. 329-339.

2. Lewinski, N.; Colvin, V.; Drezek, R. Cytotoxicity of nanoparticles. Small 2008, 4, 26-49.

3. Favi, P.M.; Gao, M.; Johana Sepúlveda Arango, L.; Ospina, S.P.; Morales, M.; Pavon, J.J.; Webster, T.J. Shape and surface effects on the cytotoxicity of nanoparticles: Gold nanospheres versus gold nanostars. J. Biomed. Mater. Res. Part A 2015, doi:10.1002/jbm.a.35491.

4. Pan, Y.; Neuss, S.; Leifert, A.; Fischler, M.; Wen, F.; Simon, U.; Schmid, G.; Brandau, W.; Jahnen-Dechent, W. Size-dependent cytotoxicity of gold nanoparticles. Small 2007, 3, 1941-1949.

5. Napierska, D.; Thomassen, L.C.; Rabolli, V.; Lison, D.; Gonzalez, L.; Kirsch-Volders, M.; Martens, J.A.; Hoet, P.H. Size-dependent cytotoxicity of monodisperse silica nanoparticles in human endothelial cells. Small 2009, 5, 846-853.

6. Carlson, C.; Hussain, S.M.; Schrand, A.M.; K. Braydich-Stolle, L.; Hess, K.L.; Jones, R.L.; Schlager, J.J. Unique cellular interaction of silver nanoparticles: Size-dependent generation of reactive oxygen species. J. Phys. Chem. B 2008, 112, 13608-13619.

7. Oberdörster, G.; Oberdörster, E.; Oberdörster, J. Nanotoxicology: An emerging discipline evolving from studies of ultrafine particles. Environ. Health Perspect. 2005, 113, 823-839.

8. Handy, R.D.; Owen, R.; Valsami-Jones, E. The ecotoxicology of nanoparticles and nanomaterials: Current status, knowledge gaps, challenges, and future needs. Ecotoxicology 2008, 17, 315-325.

9. Hussain, S.; Hess, K.; Gearhart, J.; Geiss, K.; Schlager, J. In vitro toxicity of nanoparticles in BRL 3A rat liver cells. Toxicol. Vitr. 2005, 19, 975-983.

10. Brown, J.S.; Zeman, K.L.; Bennett, W.D. Ultrafine particle deposition and clearance in the healthy and obstructed lung. Am. J. Respir. Crit. Care Med. 2002, 166, 1240-1247. 
11. Holsapple, M.P.; Farland, W.H.; Landry, T.D.; Monteiro-Riviere, N.A.; Carter, J.M.; Walker, N.J.; Thomas, K.V. Research strategies for safety evaluation of nanomaterials, part ii: Toxicological and safety evaluation of nanomaterials, current challenges and data needs. Toxicol. Sci. 2005, 88, 12-17.

12. Hoshino, A.; Fujioka, K.; Oku, T.; Nakamura, S.; Suga, M.; Yamaguchi, Y.; Suzuki, K.; Yasuhara, M.; Yamamoto, K. Quantum dots targeted to the assigned organelle in living cells. Microbiol. Immunol. 2004, 48, 985-994.

13. Salnikov, V.; Lukyanenko, Y.; Frederick, C.; Lederer, W.; Lukyanenko, V. Probing the outer mitochondrial membrane in cardiac mitochondria with nanoparticles. Biophys. J. 2007, 92, 1058-1071.

14. Donaldson, K.; Stone, V. Current hypotheses on the mechanisms of toxicity of ultrafine particles. Ann. Ist. Super. Sanita 2002, 39, 405-410.

15. Wilson, R.F. Nanotechnology: The challenge of regulating known unknowns. J. Law Med. Ethics 2006, 34, 704-713.

16. Wichmann, H.-E.; Spix, C.; Tuch, T.; Wölke, G.; Peters, A.; Heinrich, J.; Kreyling, W.G.; Heyder, J. Daily Mortality and Fine and Ultrafine Particles in Erfurt, Germany. Part I: Role Of Particle Number And Particle Mass; Research Report 98; Health Effects Institute: Boston, MA, USA, 2000.

17. Derfus, A.M.; Chan, W.C.; Bhatia, S.N. Probing the cytotoxicity of semiconductor quantum dots. Nano Lett. 2004, 4, 11-18.

18. Gupta, A.K.; Gupta, M. Synthesis and surface engineering of iron oxide nanoparticles for biomedical applications. Biomaterials 2005, 26, 3995-4021.

19. De Jong, W.H.; Borm, P.J. Drug delivery and nanoparticles: Applications and hazards. Int. J. Nanomed. 2008, 3, 133.

20. Alkilany, A.M.; Murphy, C.J. Toxicity and cellular uptake of gold nanoparticles: What we have learned so far? J. Nanoparticle Res. 2010, 12, 2313-2333.

21. Lefebvre, D.E.; Venema, K.; Gombau, L.; Valerio Jr, L.G.; Raju, J.; Bondy, G.S.; Bouwmeester, H.; Singh, R.P.; Clippinger, A.J.; Collnot, E.-M. Utility of models of the gastrointestinal tract for assessment of the digestion and absorption of engineered nanomaterials released from food matrices. Nanotoxicology 2015, 9, 523-542.

22. Bellmann, S.; Carlander, D.; Fasano, A.; Momcilovic, D.; Scimeca, J.A.; Waldman, W.J.; Gombau, L.; Tsytsikova, L.; Canady, R.; Pereira, D.I. Mammalian gastrointestinal tract parameters modulating the integrity, surface properties, and absorption of food-relevant nanomaterials. WIREs Nanomed. Nanobiotechnol. 2015, 7, 609-622.

23. Gliga, A.R.; Skoglund, S.; Wallinder, I.O.; Fadeel, B.; Karlsson, H.L. Size-dependent cytotoxicity of silver nanoparticles in human lung cells: The role of cellular uptake, agglomeration and ag release. Part. Fibre Toxicol. 2014, 11, 11.

24. Qiao, H.; Liu, W.; Gu, H.; Wang, D.; Wang, Y. The transport and deposition of nanoparticles in respiratory system by inhalation. J. Nanomater. 2015, 2015, 394507.

25. Braakhuis, H.M.; Cassee, F.R.; Fokkens, P.H.; de la Fonteyne, L.J.; Oomen, A.G.; Krystek, P.; de Jong, W.H.; van Loveren, H.; Park, M.V. Identification of the appropriate dose metric for pulmonary inflammation of silver nanoparticles in an inhalation toxicity study. Nanotoxicology 2015, doi:10.3109/17435390.2015.1012184. 
26. Varna, M.; Ratajczak, P.; Ferreira, I.; Leboeuf, C.; Bousquet, G.; Janin, A. In vivo distribution of inorganic nanoparticles in preclinical models. J. Biomater. Nanobiotechnol. 2012, 3, 18986.

27. Albanese, A.; Tang, P.S.; Chan, W.C. The effect of nanoparticle size, shape, and surface chemistry on biological systems. Annu. Rev. Biomed. Eng. 2012, 14, 1-16.

28. Ballou, B.; Lagerholm, B.C.; Ernst, L.A.; Bruchez, M.P.; Waggoner, A.S. Noninvasive imaging of quantum dots in mice. Bioconjug. Chem. 2004, 15, 79-86.

29. De Jong, W.H.; Hagens, W.I.; Krystek, P.; Burger, M.C.; Sips, A.J.; Geertsma, R.E. Particle size-dependent organ distribution of gold nanoparticles after intravenous administration. Biomaterials 2008, 29, 1912-1919.

30. Zhao, F.; Zhao, Y.; Liu, Y.; Chang, X.; Chen, C.; Zhao, Y. Cellular uptake, intracellular trafficking, and cytotoxicity of nanomaterials. Small 2011, 7, 1322-1337.

31. Kou, L.; Sun, J.; Zhai, Y.; He, Z. The endocytosis and intracellular fate of nanomedicines: Implication for rational design. Asian J. Pharm. Sci. 2013, 8, 1-10.

32. Li, W.; Chen, C.; Ye, C.; Wei, T.; Zhao, Y.; Lao, F.; Chen, Z.; Meng, H.; Gao, Y.; Yuan, H. The translocation of fullerenic nanoparticles into lysosome via the pathway of clathrin-mediated endocytosis. Nanotechnology 2008, 19, 145102.

33. Greulich, C.; Diendorf, J.; Simon, T.; Eggeler, G.; Epple, M.; Köller, M. Uptake and intracellular distribution of silver nanoparticles in human mesenchymal stem cells. Acta Biomater. 2011, 7, 347-354.

34. Harush-Frenkel, O.; Debotton, N.; Benita, S.; Altschuler, Y. Targeting of nanoparticles to the clathrin-mediated endocytic pathway. Biochem. Biophys. Res. Commun. 2007, 353, 26-32.

35. Oh, J.M.; Choi, S.J.; Lee, G.E.; Kim, J.E.; Choy, J.H. Inorganic metal hydroxide nanoparticles for targeted cellular uptake through clathrin-mediated endocytosis. Chem. Asian J. 2009, 4, 67-73.

36. Jiang, X.; Röcker, C.; Hafner, M.; Brandholt, S.; Dörlich, R.M.; Nienhaus, G.U. Endo-and exocytosis of zwitterionic quantum dot nanoparticles by live hela cells. ACS Nano 2010, 4, 6787-6797.

37. Jiang, X.; Dausend, J.; Hafner, M.; Musyanovych, A.; Röcker, C.; Landfester, K.; Mailänder, V.; Nienhaus, G.U. Specific effects of surface amines on polystyrene nanoparticles in their interactions with mesenchymal stem cells. Biomacromolecules 2010, 11, 748-753.

38. Kam, N.W.S.; Liu, Z.; Dai, H. Carbon nanotubes as intracellular transporters for proteins and DNA: An investigation of the uptake mechanism and pathway. Angew. Chem. 2006, 118, 591-595.

39. Huang, D.-M.; Hung, Y.; Ko, B.-S.; Hsu, S.-C.; Chen, W.-H.; Chien, C.-L.; Tsai, C.-P.; Kuo, C.-T.; Kang, J.-C.; Yang, C.-S. Highly efficient cellular labeling of mesoporous nanoparticles in human mesenchymal stem cells: Implication for stem cell tracking. FASEB J. 2005, 19, 2014-2016.

40. Jiang, W.; Kim, B.Y.; Rutka, J.T.; Chan, W.C. Nanoparticle-mediated cellular response is size-dependent. Nat. Nanotechnol. 2008, 3, 145-150.

41. Bohmer, N.; Jordan, A. Caveolin-1 and CDC42 mediated endocytosis of silica-coated iron oxide nanoparticles in hela cells. Beilstein J. Nanotechnol. 2015, 6, 167-176.

42. Klingberg, H.; Oddershede, L.B.; Loeschner, K.; Larsen, E.H.; Loft, S.; Møller, P. Uptake of gold nanoparticles in primary human endothelial cells. Toxicol. Res. 2015, 655-666. 
43. Suresh, D.; Zambre, A.; Chanda, N.; Hoffman, T.J.; Smith, C.J.; Robertson, J.D.; Kannan, R. Bombesin peptide conjugated gold nanocages internalize via clathrin mediated endocytosis. Bioconjug. Chem. 2014, 25, 1565-1579.

44. Zhang, L.W.; Yang, J.; Barron, A.R.; Monteiro-Riviere, N.A. Endocytic mechanisms and toxicity of a functionalized fullerene in human cells. Toxicol. Lett. 2009, 191, 149-157.

45. Partlow, K.C.; Lanza, G.M.; Wickline, S.A. Exploiting lipid raft transport with membrane targeted nanoparticles: A strategy for cytosolic drug delivery. Biomaterials 2008, 29, 3367-3375.

46. Nishikawa, T.; Iwakiri, N.; Kaneko, Y.; Taguchi, A.; Fukushima, K.; Mori, H.; Morone, N.; Kadokawa, J.-i. Nitric oxide release in human aortic endothelial cells mediated by delivery of amphiphilic polysiloxane nanoparticles to caveolae. Biomacromolecules 2009, 10, 2074-2085.

47. Mo, Y.; Lim, L.Y. Mechanistic study of the uptake of wheat germ agglutinin-conjugated plga nanoparticles by A549 cells. J. Pharm. Sci. 2004, 93, 20-28.

48. Wang, Z.; Tiruppathi, C.; Minshall, R.D.; Malik, A.B. Size and dynamics of caveolae studied using nanoparticles in living endothelial cells. ACS Nano 2009, 3, 4110-4116.

49. Wang, L.; Liu, Y.; Li, W.; Jiang, X.; Ji, Y.; Wu, X.; Xu, L.; Qiu, Y.; Zhao, K.; Wei, T. Selective targeting of gold nanorods at the mitochondria of cancer cells: Implications for cancer therapy. Nano Lett. 2010, 11, 772-780.

50. Dausend, J.; Musyanovych, A.; Dass, M.; Walther, P.; Schrezenmeier, H.; Landfester, K.; Mailänder, V. Uptake mechanism of oppositely charged fluorescent nanoparticles in hela cells. Macromol. Biosci. 2008, 8, 1135-1143.

51. Ruan, G.; Agrawal, A.; Marcus, A.I.; Nie, S. Imaging and tracking of tat peptide-conjugated quantum dots in living cells: New insights into nanoparticle uptake, intracellular transport, and vesicle shedding. J. Am. Chem. Soc. 2007, 129, 14759-14766.

52. Meng, H.; Yang, S.; Li, Z.; Xia, T.; Chen, J.; Ji, Z.; Zhang, H.; Wang, X.; Lin, S.; Huang, C. Aspect ratio determines the quantity of mesoporous silica nanoparticle uptake by a small gtpase-dependent macropinocytosis mechanism. ACS Nano 2011, 5, 4434-4447.

53. Trefry, J.C.; Wooley, D.P. Silver nanoparticles inhibit vaccinia virus infection by preventing viral entry through a macropinocytosis-dependent mechanism. J. Biomed. Nanotechnol. 2013, 9, 1624-1635.

54. Gao, H.; Yang, Z.; Zhang, S.; Cao, S.; Shen, S.; Pang, Z.; Jiang, X. Ligand modified nanoparticles increases cell uptake, alters endocytosis and elevates glioma distribution and internalization. Sci. Rep. 2013, 3, 2543.

55. Chithrani, B.D.; Ghazani, A.A.; Chan, W.C. Determining the size and shape dependence of gold nanoparticle uptake into mammalian cells. Nano Lett. 2006, 6, 662-668.

56. Klabunde, K.J.; Stark, J.; Koper, O.; Mohs, C.; Park, D.G.; Decker, S.; Jiang, Y.; Lagadic, I.; Zhang, D. Nanocrystals as stoichiometric reagents with unique surface chemistry. J. Phys. Chem. 1996, 100, 12142-12153.

57. Campbell, C.T.; Parker, S.C.; Starr, D.E. The effect of size-dependent nanoparticle energetics on catalyst sintering. Science 2002, 298, 811-814.

58. Suttiponparnit, K.; Jiang, J.; Sahu, M.; Suvachittanont, S.; Charinpanitkul, T.; Biswas, P. Role of surface area, primary particle size, and crystal phase on titanium dioxide nanoparticle dispersion properties. Nanoscale Res. Lett. 2011, 6, 27. 
59. Nel, A.; Xia, T.; Madler, L.; Li, N. Toxic potential of materials ar the nanolevel. Science 2006, $311,622-627$.

60. Oberdorster, G.; Maynard, A.; Donaldson, K.; Castranova, V.; Fitzpatrick, J.; Ausman, K.; Carter, J.; Karn, B.; Kreyling, W.; Lai, D.; et al. Principles for characterizing the potential human health effects from exposure to nanomaterials: Elements of a screening strategy. Part. Fibre Toxicol. 2005, 2, 8-43.

61. Duffine, R.; Tran, C.L.; Clouter, A.; Brown, D.M.; MacNee, W.; Stone, V.; Donaldson, K. The importance of surface area and specific reactivity in the acute pulmonary inflammatory respones to particles. Ann. Occup. Hyg. 2002, 46, 242-245.

62. Stoeger, T.; Reinhard, C.; Takenaka, S.; Schroeppel, A.; Karg, E.; Ritter, B.; Heyder, J.; Schulz, H. Instillation of six different ultrafine carbon particles indicates a surface area threshold dose for acute lung inflammation in mice. Environm. Health Perspect. 2005, 114, 328-333.

63. Sager, T.M.; Kommineni, C.; Castranova, V. Pulmonary response to intratracheal instillation of ultrafine versus fine titanium dioxide: Role of particle surface area. Part. Fibre Toxicol. 2008, 5, $17-32$.

64. Sager, T.M.; Castranova, V. Surface area of particle administered versus mass in determining the pulmonary toxicity of ultrafine and fine carbon black: Comparison to ultrafine titanium dioxide. Part. Fibre Toxicol. 2009, 6, 15-46.

65. Warheit, D.B.; Reed, K.L.; Sayes, C.M. A role for nanoparticle surface reactivity in facilitating pulmonary toxicity and development of a base set of hazard assays as a component of nanoparticle risk management. Inhal. Toxicol. 2009, 21, 61-67.

66. Monteiller, C.; Tran, L.; MacNee, W.; Faux, S.; Jones, A.; Miller, B.; Donaldson, K. The pro-inflammatory effects of low-toxicity low-solubility particles, nanoparticles and fine particles, on epithelial cells in vitro: The role of surface area. Occup. Environ. Med. 2007, 64, 609-615.

67. Rabolli, V.; Thomassen, L.C.; Uwambayinema, F.; Martens, J.A.; Lison, D. The cytotoxic activity of amorphous silica nanoparticles is mainly influenced by surface area and not by aggregation. Toxicol. Lett. 2011, 206, 197-203.

68. Lin, W.; Huang, Y.W.; Zhou, X.D.; Ma, Y. In vitro toxicity of silica nanoparticles in human lung cancer cells. Toxicol. Appl. Pharm. 2006, 217, 252-259.

69. Wang, A.Z.; Langer, R.; Farokhzad, O.C. Nanoparticle delivery of cancer drugs. Annu. Rev. Med. 2012, 63, 185-198.

70. Verma, A.; Stellacci, F. Effect of surface properties on nanoparticle-cell interactions. Small 2010, $6,12-21$.

71. Albanese, A.; Lam, A.K.; Sykes, E.A.; Rocheleau, J.V.; Chan, W.C. Tumour-on-a-chip provides an optical window into nanoparticle tissue transport. Nat. Commun. 2013, 4, 2718.

72. Valencia, P.M.; Farokhzad, O.C.; Karnik, R.; Langer, R. Microfluidic technologies for accelerating the clinical translation of nanoparticles. Nat. Nanotechnol. 2012, 7, 623-629.

73. Esch, M.B.; King, T.L.; Shuler, M.L. The role of body-on-a-chip devices in drug and toxicity studies. Annu. Rev. Biomed. Eng. 2011, 13, 55-72.

74. Toh, Y.C.; Lim, T.C.; Tai, D.; Xiao, G.; van Noort, D.; Yu, H. A microfluidic 3D hepatocyte chip for drug toxicity testing. Lab Chip 2009, 9, 2026-2035. 
75. He, C.; Hu, Y.; Yin, L.; Tang, C.; Yin, C. Effects of particle size and surface charge on cellular uptake and biodistribution of polymeric nanoparticles. Biomaterials 2010, 31, 3657-3666.

76. Hirn, S.; Semmler-Behnke, M.; Schleh, C.; Wenk, A.; Lipka, J.; Schaffler, M.; Takenaka, S.; Moller, W.; Schmid, G.; Simon, U.; et al. Particle size-dependent and surface charge-dependent biodistribution of gold nanoparticles after intravenous administration. Eur. J. Pharm. Biopharm. 2011, 77, 407-416.

77. Malam, Y.; Loizidou, M.; Seifalian, A.M. Liposomes and nanoparticles: Nanosized vehicles for drug delivery in cancer. Trends Pharm. Sci. 2009, 30, 592-599.

78. Jiang, J.; Oberdörster, G.; Biswas, P. Characterization of size, surface charge, and agglomeration state of nanoparticle dispersions for toxicological studies. J. Nanopart. Res. 2008, 11, 77-89.

79. Asati, A.; Santra, S.; Kaittanis, C.; Perez, J.M. Surface-charge-dependent cell localization and cytotoxicity of cerium oxide nanoparticles. ACS Nano 2010, 4, 5321-5331.

80. Frohlich, E. The role of surface charge in cellular uptake and cytotoxicity of medical nanoparticles. Int. J. Nanomed. 2012, 7, 5577-5591.

81. Schaeublin, N.M.; Braydich-Stolle, L.K.; Schrand, A.M.; Miller, J.M.; Hutchison, J.; Schlager, J.J.; Hussain, S.M. Surface charge of gold nanoparticles mediates mechanism of toxicity. Nanoscale 2011, 3, 410-420.

82. Cha, K.E.; Myung, H. Cytotoxic effects of nanoparticles assessed in vitro and in vivo. J. Microbiol. Biotechnol. 2007, 17, 1573-1578.

83. Huczko, A.; Lange, H.; Całko, E.; Grubek-Jaworska, H.; Droszcz, P. Physiological testing of carbon nanotubes: Are they asbestos-like? Fuller. Sci. Technol. 2001, 9, 251-254.

84. Firme, C.P.; Bandaru, P.R. Toxicity issues in the application of carbon nanotubes to biological systems. Nanomed. Nanotechnol. Biol. Med. 2010, 6, 245-256.

85. Chalupa, D.C.; Morrow, P.E.; Oberdörster, G.; Utell, M.J.; Frampton, M.W. Ultrafine particle deposition in subjects with asthma. Environ. Health Perspect. 2004, 112, 879-882.

86. Handy, R.D.; Henry, T.B.; Scown, T.M.; Johnston, B.D.; Tyler, C.R. Manufactured nanoparticles: Their uptake and effects on fish-A mechanistic analysis. Ecotoxicology 2008, 17, 396-409.

87. Baker, G.L.; Gupta, A.; Clark, M.L.; Valenzuela, B.R.; Staska, L.M.; Harbo, S.J.; Pierce, J.T.; Dill, J.A. Inhalation toxicity and lung toxicokinetics of $\mathrm{C} 60$ fullerene nanoparticles and microparticles. Toxicol. Sci. 2008, 101, 122-131.

88. Elder, A.C.P.; Gelein, R.; Finkelstein, J.N.; Cox, C.; Oberdorster, G. Pulmonary inflammatory response to inhaled ultrafine particles is modified by age, ozone exposure, and bacterial toxin. Inhal. Toxicol. 2000, 12, 227-246.

89. Oberdörster, E. Manufactured nanomaterials (fullerenes, C60) induce oxidative stress in the brain of juvenile largemouth bass. Environ. Health Perspect. 2004, 112, 1058-1062.

90. Lovern, S.B.; Klaper, R. Daphnia magna mortality when exposed to titanium dioxide and fullerene (C60) nanoparticles. Environ. Toxicol. Chem. 2006, 25, 1132-1137.

91. Lyon, D.Y.; Adams, L.K.; Falkner, J.C.; Alvarez, P.J.J. Antibacterial activity of fullerene water suspensions: Effects of preparation method and particle size. Environ. Sci. Technol. 2006, 40, 4360-4366.

92. Lyon, D.Y.; Fortner, J.D.; Sayes, C.M.; Colvin, V.L.; Hughes, J.B. Bacterial cell association and antimicrobial activity of a c60 water suspension. Environ. Toxicol. Chem. 2005, 24, 2757-2762. 
93. Li, Z.; Hulderman, T.; Salmen, R.; Chapman, R.; Leonard, S.S.; Young, S.H.; Shvedova, A.; Luster, M.I.; Simeonova, P.P. Cardiovascular effects of pulmonary exposure to single-wall carbon nanotubes. Environ. Health Perspect. 2007, 115, 377-382.

94. Bantz, C.; Koshkina, O.; Lang, T.; Galla, H.-J.; Kirkpatrick, C.J.; Stauber, R.H.; Maskos, M. The surface properties of nanoparticles determine the agglomeration state and the size of the particles under physiological conditions. Beilstein J. Nanotechnol. 2014, 5, 1774-1786.

95. Donaldson, K.; Aitken, R.; Tran, L.; Stone, V.; Duffin, R.; Forrest, G.; Alexander, A. Carbon nanotubes: A review of their properties in relation to pulmonary toxicology and workplace safety. Toxicol. Sci. 2006, 92, 5-22.

(C) 2015 by the authors; licensee MDPI, Basel, Switzerland. This article is an open access article distributed under the terms and conditions of the Creative Commons Attribution license (http://creativecommons.org/licenses/by/4.0/). 